\title{
Word/picture interference effects in free recall
}

\author{
STEPHANIE BOESCH and LIONEL STANDING \\ Bishop's University, Lennoxville, Quebec, Canada
}

\begin{abstract}
In this study, we investigated how memory for pictures, concrete words, and abstract words is affected by a second learning task, given between the primary learning task and recall. Three secondary tasks were employed (pictures, concrete words, and abstract words), in a $3 \times 3$ design $(N=90)$. It was predicted that (1) most interference would be caused by a second learning task using the same type of material as in the original task and (2) mean recall would be increased as the second task was made more dissimilar to the first. Parallel predictions to the above were made for the recall of the secondary task items, as a function of interference by the first. These predictions were supported in 10 of 12 instances, but, in two cases, a word-suppression effect was noted, whereby initial picture stimuli suppressed the learning of subsequent word stimuli.
\end{abstract}

Many studies suggest that some types of stimulus material are much easier to learn than are others, the usual ordering from easiest to hardest being pictures, concrete words, and abstract words (Paivio, 1971; Standing, 1973).

Less is known of how two different types of material interact or interfere with each other when they are learned successively. The basic paradigm involved here is that one set of stimuli is learned (the primary task), followed immediately by another set (the secondary task); then, memory for both the primary and the secondary material is tested. The simplest hypothesis of interference effects is that, as the primary and the secondary material are made more similar to each other, more mutual interference will be caused, causing poorer recall.

In line with the above prediction, Atwood (1971) found that viewing a visual digit, as an intervening task after learning an imaginal or concrete phrase, reduced the recall of the concrete phrase. However, when the sentences were abstract so that it was difficult to construct images, an auditory digit task produced as much interference as the visual digit. In general, task dissimilarity reduces proactive and retroactive interference effects (see Klatzky, 1975, p. 103).

Following Paivio's (1971) dual-coding hypothesis, we postulate that abstract words and pictures are extremely dissimilar (represented mainly as verbal and visual codes in memory, respectively), whereas concrete or highimagery words occupy an intermediate position (represented as dual visual and verbal codes) and are therefore moderately similar to both of the previous stimulus types. We therefore predict that the recall of a given type of material from the primary learning task (pictures, concrete words, or abstract words in the present study)

This study was reported in an honors thesis prepared by the first author and supervised by the second author. Reprints may be obtained from L. Standing, Department of Psychology, Bishop's University, Lennoxville, Quebec J1M 1Z7, Canada. will increase as the secondary task involves material that is more dissimilar to the primary task. For example, when abstract words are used for the primary learning task, we predict that recall will be impaired increasingly by the use of pictures, concrete words, and abstract words as the secondary learning material. A parallel set of predictions is made for the recall of the secondary material, as a function of the interference caused by the first task.

\section{METHOD}

\section{Subjects}

The subjects were 90 psychology students, averaging approximately 21 years of age.

\section{Apparatus and Materials}

The learning stimuli were 120 pictures, 120 concrete words, and 120 abstract words. The picture-word sets of Snodgrass and Vanderwart (1980) were employed for the picture and concrete-word stimuli (line drawings and single-word noun descriptors, respectively); no item was used if its word-picture equivalent was employed. The abstract nouns were randomly selected from a dictionary. The stimuli were assessed on a 7-point imagery scale by three raters, and only those words that were rated 1 and 7 , respectively, were employed for the abstract- and concrete-word stimuli. All stimuli were shown by means of a slide projector, at 5-sec intervals.

\section{Design and Procedure}

A $3 \times 3 \times 2$ design was used. The first factor (between subjects) was the type of primary task material; the second factor (within subjects) was the type of secondary task material. The third factor (between subjects) was order of testing: the two counterbalanced testing orders represented, respectively, a sequence with pictures, concrete words, then abstract words as the secondary task, or the reverse sequence.

Each subject was randomly assigned to one of the three primary task materials (30 to each) and was given three successive tests. Each test used the same type of primary task material (with novel items), but the type of secondary task material was different in each, according to the two counterbalanced testing orders. In each test, the subjects first viewed the primary task items ( 30 items), followed immediately by the secondary task items (30 items). They then attempted to recall the primary list within $2 \mathrm{~min}$, in any order, and the secondary list within another $2 \mathrm{~min}$. All recall was by written response; minor spelling errors were ignored. Recall of pictures was performed by writing the equivalent verbal form (e.g., CAT for a picture of a cat). 
Table 1

Mean Items Correctly Recalled from the Primary Task, as a Function of Type of Material in the Primary and Secondary Tasks

\begin{tabular}{|c|c|c|c|c|c|c|}
\hline \multirow[b]{3}{*}{ Primary Task } & \multicolumn{6}{|c|}{ Secondary Task } \\
\hline & \multicolumn{2}{|c|}{ Pictures } & \multicolumn{2}{|c|}{$\begin{array}{c}\text { Concrete } \\
\text { Words }\end{array}$} & \multicolumn{2}{|c|}{$\begin{array}{l}\text { Abstract } \\
\text { Words }\end{array}$} \\
\hline & $M$ & $S D$ & $M$ & $S D$ & $M$ & $S D$ \\
\hline Pictures & 8.8 & 3.7 & 9.2 & 3.2 & 11.33 & 3.5 \\
\hline Concrete Words & 11.73 & 5.2 & 9.9 & 4.7 & 11.27 & 6.1 \\
\hline Abstract Words & 8.4 & 3.3 & 7.3 & 3.5 & 5.9 & 2.8 \\
\hline
\end{tabular}

Note $-n=30$.

\section{RESULTS}

The subjects were given one point for each item correctly recalled. The mean numbers of items recalled from the primary task are shown in Table 1, and those from the secondary task in Table 2 .

From these tables, the effect on recall of the degree of similarity between primary and secondary tasks may be calculated. We take the condition involving the same type of material in both primary and secondary tasks as representing a baseline in each case (e.g., abstract wordsabstract words), and then by subtraction, find the net gain (or loss) in recall when the primary and secondary materials differ from each other.

We assume that the materials (pictures, concrete words, and abstract words) may be represented on an ordinal scale of concreteness (with values of 1,2 , and 3 ). Therefore, for example, when we move from the abstract wordsabstract words condition to the abstract words-concrete words condition, we introduce a difference of 1 category between the two tasks (and observe that recall in the primary task thereby increases from the baseline of 5.9 to 7.3 items). If we move to the abstract words-pictures condition, a difference of 2 categories is now involved (and recall increases from the baseline to 8.4 items). Similar calculations were made for the various primary and
Table 2

Mean Items Correctly Recalled from the Secondary Task, as a Function of Type of Material in the Primary and Secondary Tasks

\begin{tabular}{|c|c|c|c|c|c|c|}
\hline \multirow[b]{3}{*}{ Secondary Task } & \multicolumn{6}{|c|}{ Primary Task } \\
\hline & \multicolumn{2}{|c|}{ Pictures } & \multicolumn{2}{|c|}{$\begin{array}{c}\text { Concrete } \\
\text { Words }\end{array}$} & \multicolumn{2}{|c|}{$\begin{array}{c}\text { Abstract } \\
\text { Words }\end{array}$} \\
\hline & $M$ & $S D$ & $\boldsymbol{M}$ & $S D$ & $M$ & $S D$ \\
\hline Pictures & 8.67 & 4.0 & 11.4 & 3.6 & 12.7 & 3.8 \\
\hline Concrete Words & 6.6 & 4.38 & 9.7 & 5.65 & 10.84 & 4.27 \\
\hline Abstract Words & 5.47 & 2.08 & 7.24 & 3.19 & 3.94 & 2.04 \\
\hline
\end{tabular}

Note $-n=30$.

secondary tasks, with results that are summarized in Table 3 .

In Table 3, 10 out of 12 values fall into the predicted pattern, in that they are positive, and 2-category dissimilarity between the primary and secondary tasks enhances recall more than does 1-category dissimilarity. Although not all differences attain significance, with only two exceptions, the similarity principle of interference effects is supported by these data. The first exception is that the pictures-concrete words condition produced lower recall of the concrete words than did the concrete wordsconcrete words condition. The second is that the abstract words were more poorly recalled in the pictures-abstract words condition than in the concrete words-abstract words condition (though better than in the abstract wordsabstract words condition). Both of these exceptions to the similarity principle represent a suppression of recall for verbal stimuli due to preceding picture stimuli.

\section{DISCUSSION}

The results generally support the hypothesis that the mutual interference between two successive learning tasks is greatest when the two tasks involve the same type of material. Thus, when dissimilarity is introduced, proactive and retroactive inhibition processes are reduced by moving to a different type of learning material in the second task.

Table 3

Increase in Recall When Different Types of Material

Were Used for the Primary and Secondary Tasks

\begin{tabular}{|c|c|c|c|c|}
\hline \multirow[b]{3}{*}{ Recall of } & \multicolumn{4}{|c|}{$\begin{array}{l}\text { Difference in Concreteness Between Primary } \\
\text { and Secondary Task Materials }\end{array}$} \\
\hline & \multicolumn{2}{|c|}{1 Category } & \multicolumn{2}{|c|}{2 Categories } \\
\hline & $\begin{array}{l}\text { Interfering } \\
\text { Stimuli }\end{array}$ & $\begin{array}{c}\text { Recall } \\
\text { Increase }\end{array}$ & $\begin{array}{l}\text { Interfering } \\
\text { Stimuli }\end{array}$ & $\begin{array}{c}\text { Recall } \\
\text { Increase }\end{array}$ \\
\hline \multicolumn{5}{|l|}{ (Primary Task) } \\
\hline $\begin{array}{l}\text { Pictures } \\
\text { Concrete words }\end{array}$ & $\begin{array}{l}\text { Concrete words } \\
\text { Pictures } \\
\text { Abstract words }\end{array}$ & $\begin{array}{l}0.4 \\
1.83 \\
1.37\end{array}$ & Abstract words & $2.53 *$ \\
\hline Abstract words & Concrete words & 1.4 & Pictures & $2.5^{*}$ \\
\hline \multicolumn{5}{|l|}{ (Secondary Task) } \\
\hline $\begin{array}{l}\text { Pictures } \\
\text { Concrete words }\end{array}$ & $\begin{array}{l}\text { Concrete words } \\
\text { Pictures } \\
\text { Abstract words }\end{array}$ & $\begin{array}{l}2.73 * \\
-3.1 \dagger \\
1.14^{*} \\
3.3 t\end{array}$ & Abstract words & $4.03 \dagger$ \\
\hline Abstract words & Concrete woras & & Pictures & $1.53 \dagger$ \\
\hline
\end{tabular}


However, an exception is encountered in that recall of words, especially concrete words, is depressed when the word list has been preceded by a picture-learning task. This is unexpected, because pictorial material itself is not difficult to learn (the highest treatment mean observed was that for recall of pictures preceded by abstract words). This wordsuppression effect seems not to have been noted in previous studies of interference phenomena (e.g., Anderson \& Paulson, 1978). It may occur because the residual traces of picture stimuli are particularly strong (Standing, 1973). Thus, a distracting image may be present when the subject switches from learning pictures to learning words, disrupting the focused attention that is needed to encode them.

\section{REFERENCES}

Anderson, J., \& Paulson, R. (1978). Interference in memory for pictorial information. Cognitive Psychology, 10, 178-202.
Atwood, G. (1971). An experimental study of visual imagination and memory. Cognitive Psychology, 2, 290-299.

KlatZKY, R. (1975). Human memory. San Francisco: Freeman.

PAIvio, A. (1971). Imagery and verbal processes. New York: Holt, Rinehart \& Winston.

Snodgrass, J., \& Vanderwart, M. (1980). Picture/word slide set: Experiments in human memory. Bayport, NY: Life Science Associates.

STANDING. L. (1973). Learning 10,000 pictures. Quarterly Journal of Experimental Psychology, 25, 207-222.

(Manuscript received August 14, 1989.) 